\title{
A Review on Hybrid solar/wind/ hydro power generation system
}

\author{
Bhushan D. Agarkar $^{+*}$ and Shivprakash B. Barve ${ }^{\dagger}$ \\ †Department of Mechanical Engineering, MIT College of Engineering, Pune-411038, India \\ Accepted 03 March 2016, Available online 15 March 2016, Special Issue-4 (March 2016)
}

\begin{abstract}
In this paper we studied the various renewable energy resources \& which will be used for the development of electricity. The main source of energy is solar energy, wind energy, hydro energy. This paper provides a review on the hybrid power generation i.e. combination of two or more energy sources. The hybrid power generation systems will in turn be used for charging the batteries. The Hybrid (Wind / hydro / solar) system is more economical, environmental friendly. The power generation capacity of hybrid system is more than the power generation capacity of the individual system. The results showing the power output of individual system and hybridized system obtained from Metrological Station for the period of five years 2010-2015 is used for comparison between the different hybrid systems.
\end{abstract}

Keywords: Solar energy, Wind energy, Hydro energy, Hybrid system, Renewable energy.

\section{Introduction}

The design of a solar tracker system and their implementation dedicated to the PV conversion panels. In this study of tilt angle is a major point. The net gain of $15 \%-35 \%$ from tracking PV modules in fixed position toward the sun. The most popular single axis system is used for tracking the sun position by tilting angle. The multi-agent system is beneficial and it is used for tracking the sun in the photovoltaic plant. This system is beneficial, easy installation and low cost so it is also a preferable for the solar power production. This system consumes less power. It has a problem of generating the tracking trajectories for PV tracking systems is computational complex. Assuming this for a year is time-consuming. The exact value of this improvement depends on the installation. (Khadidja et al, 2014).

The amount of energy delivered to the battery through the solar and wind energy combination is controlled by the hybrid controller. It is directly associated to the relay which designed a distinctive household load with wind solar hybrid system with the charge controller to charge a battery. The wind solar hybrid system mainly consists of the wind turbine and solar panel. The energy produced from the two with a combination is used for household purpose. As per requirement the energy form the battery is use given to the load. Controller had an electronic component such as microcontroller ATMEGA8535, LCD display (+5 V (16X2)) and An IC ULN2803. An IC
ULN2803 is used for over current prevention process if occurs. At that time, it gives an indication alarm. The estimated Total Cost of wind and solar hybrid power $=$ Rs. 1,00,213 and had a payback period is 1 year. So, Wind and Solar Hybrid System is more resourceful for rural area where electricity is not easily accessible. (Vadirajacharya et al, 2012).

The Savonius type wind turbine model is used. In this model experiment is carried out on 2, 3 and 4 blades of the wind turbine. The effect of blades nonperformance calculated. This shows the tip speed ratio, torque and power coefficient according to wind speed. Pressure distribution of wind turbine shown in ANSYS 13.0 software. This model had optimum performance when used with 3 blades at their high tip ratio. The highest tip ratio is achieved in Savonius model is 0.555 at a wind speed $7 \mathrm{~m} / \mathrm{s}$ (Wenehenubun et.al, 2015). Following conclusion remarks are

1) The rotation of the rotor is depending on a number of blades. The wind turbine having three blades produce high rotational speed and tip ration than 4 blades or any other. The highest tip speed ratio is 0.555 at a wind speed of $7 \mathrm{~m} / \mathrm{s}$.

2) Four blades Wind turbine rotor had the highest torque.

3) Four blades wind turbine working good performance at lower tip speed ratio, but three blades wind turbine had the best performance at higher tip speed ratio.

Design of hybrid system is a process of selecting the reliable components and its sizing to provide cheap, efficient, reliable and cost effective renewable energy. This system is also utilized for irrigation purpose. The 
submersible pump consumes 204 units per day on an average to irrigate the 1.5 acres for mango crop. The cost calculation of the wind-solar hybrid system is done in that. This data will be useful for small scale wind-solar hybrid system manufacturers. The major advantage of wind - solar hybrid energy system is that when used together, reduces the cost of the system. This analysis gives the guideline of engineers to develop the hybrid system to meet the energy demand with optimum cost. In rural area cannot reach electricity with limited cost or do not access the convection commercial fuel. So it beneficial to design hybrid system for irrigation purpose in the rural area (Shivrath et al, 2012)

The wind turbine is designed in such way that the optimum tip speed ratio extracts maximum power with available wind speed when turbine rotor passes through air it leaves the turbulence wake in the path of the stream. If next blade of revolving rotor comes in the region of the wake when the air is still turbulent it will not able to remove power from the wind turbine resourcefully. And it comes into high vibration. If rotor blade rotates slowly then the air striking each rotor blade would no longer be in turbulence. This is another way to select the tip speed ratio so that rotor blade does not pass through turbulent air (Ragheb et at,)

\section{Power potential}

Hybrid power systems constitutes of a number of storage components and power generators. It is designed to meet the energy demand of rural area. To fit the local geographic conditions and other specifications, small hydro plants wind generators, PV generators and other sources of electrical energy are added. For developing a hybrid system for a specific location, it is essential to know the particular energy demand and the resources available for that place location. So, for a particular site location the energy planners must study the potential available resources on solar, wind and hydro energy.

\subsection{Solar energy potential}

India has an average annual temperature ranges between from $25^{\circ} \mathrm{C}-27.5{ }^{\circ} \mathrm{C}$. Hence India has enormous solar energy potential. Photovoltaic (PV) cells are placed on the roof top of houses or commercial buildings, to collect the solar energy. Solar collectors such as mirrors or parabolic dishes that can move and track the sun throughout the day are also used. For concentrated lighting in buildings similar mechanism is used. Solar has numerous domestics, industrial application. India being a tropical country receives solar radiation about 3,000 hours of sunshine in a subsequent year which is equal to more than 5,000 trillion $\mathrm{kWh}$. In all part of India, it receives $4-7 \mathrm{kWh}$ of solar radiation per square meter.

\subsection{Wind energy potential}

The strong south-west summer monsoon, which starts in May-June, influences the wind energy in India. In this time cool, humid air moves towards the land in October the north east winter monsoon starts, when the cool, dry air moves towards the ocean. In the months march to August, the winds are uniformly strong over the whole Indian Peninsula region but it except the eastern peninsular coast. Wind speeds in month November to march are relatively weak though higher speed winds are on the Tamil Nadu coastline.

\subsection{Hydro energy potential}

The small hydro power (SHP) Development is economical than comparing other sources of renewable energy such as the wind, solar or biomass .the SHP life span is highest among other renewable energy sources. The output of SHP varies only gradually from day to day and not from minute to minute as in wind

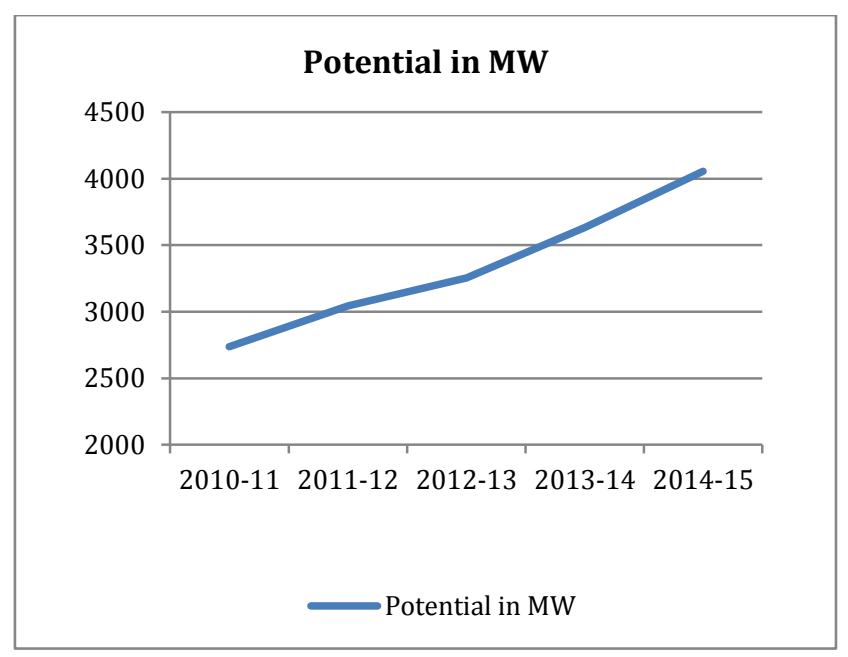

Fig. 1 Growth of identified SHP potential in India

\subsection{Hybrid energy potential}

The current energy consumption rate proved that coal resources should last for about 200 years, oil and natural gases for 40 years and 60 years respectively.

\section{Renewable energy by installed capcity in India}

घmall Hydro Power $\square$ Solar Power $\square$ wind power

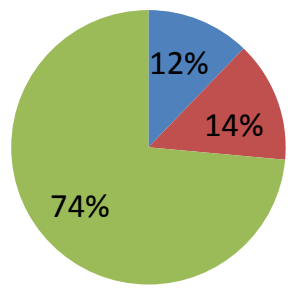

Fig. 2 Renewable energy by installed capacity in India 
It is predicted that there would be $40 \%$ increase in the renewable energy production over the span of next 5 years. Wind energy is expanded globally over $25 \%$ to $35 \%$. So, it is named as world's fastest growing energy source. Hydro is the second largest available renewable resource and its energy market is around 20\% to $30 \%$ annually. Solar power technologies are predicted to be $4.9 \%$ of global renewable energy sources.

Total energy of the hybrid will be the supply from the solar PV, wind turbine and hydro. As show in the equation below

$$
\begin{aligned}
& \mathrm{P}_{\mathrm{HY}}=\mathrm{P}_{\mathrm{PV}}+\mathrm{P}_{\mathrm{W}} \\
& \mathrm{P}_{\mathrm{HY}}=\mathrm{P}_{\mathrm{PV}}+\mathrm{P}_{\mathrm{HYDRO}} \\
& \mathrm{P}_{\mathrm{HY}}=\mathrm{P}_{\mathrm{W}}+\mathrm{P}_{\text {HYDRO }}
\end{aligned}
$$

Where $\mathrm{P}_{\mathrm{HY}}$ is power generated by the hybrid system $\mathrm{P}_{\mathrm{PV}}$ is the power generated by the solar PV system $\mathrm{Pw}$ is the power generated by hydraulic turbine

\section{Comparison and Discussion}

Figure3. shows the power producing capacity of the individual systems over the span of five years 20102015. This figure shows that the power generated by from (solar/wind/hydro) in 2014-15 is highest. The individual capacities are: Wind energy about 23,444 MW; Hydro energy about 4055 MW and solar energy about 3,743MW. Energy production from 2010 to 2014 is gradually increased year by year.

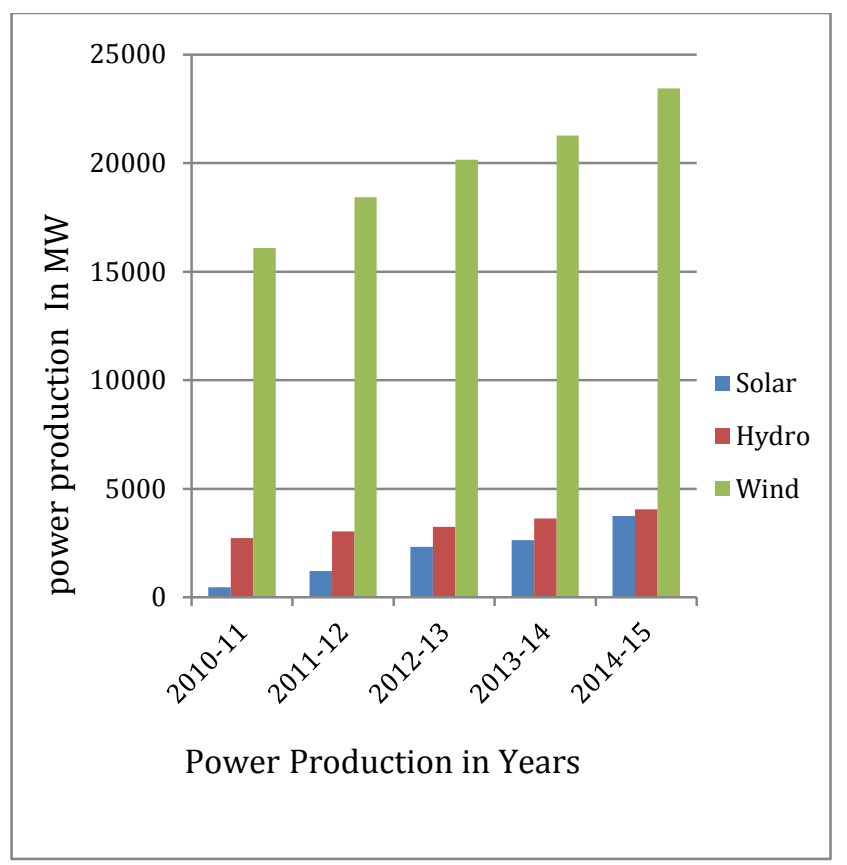

Fig. 3 Power produced by (wind/solar/hydro) system

Figure 4 shows the power production PV, wind turbine and hybrid system. The highest power obtained from the wind is more than the PV array. Figure 4 also shows the power generated from hybrid system is the highest in year of 2014-15 where the power production is about $2743 \mathrm{MW}$ from solar, 23444 from wind and 27184 from the hybrid system.

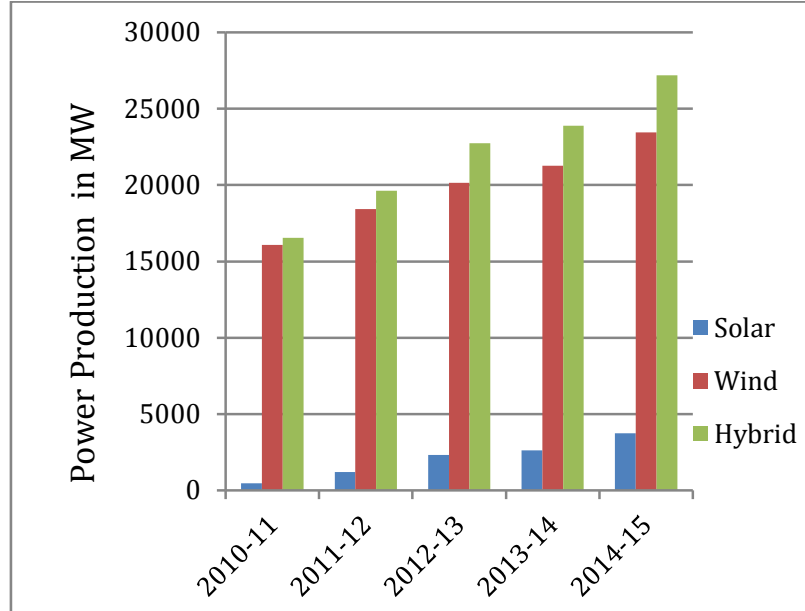

Power Production in Years

Fig. 4 Comparison of solar wind and hybrid system

Figure 5 shows the power production by the hydro, wind turbine as well as power production by hybrid system. The highest power obtained from the wind is more than Hydraulic turbine. Figure 5 also shows that power generated from hybrid system is the highest in year 2014-15 where power production is about 4055 MW from the hydro, 23444 from wind and 27499 from the hybrid system.

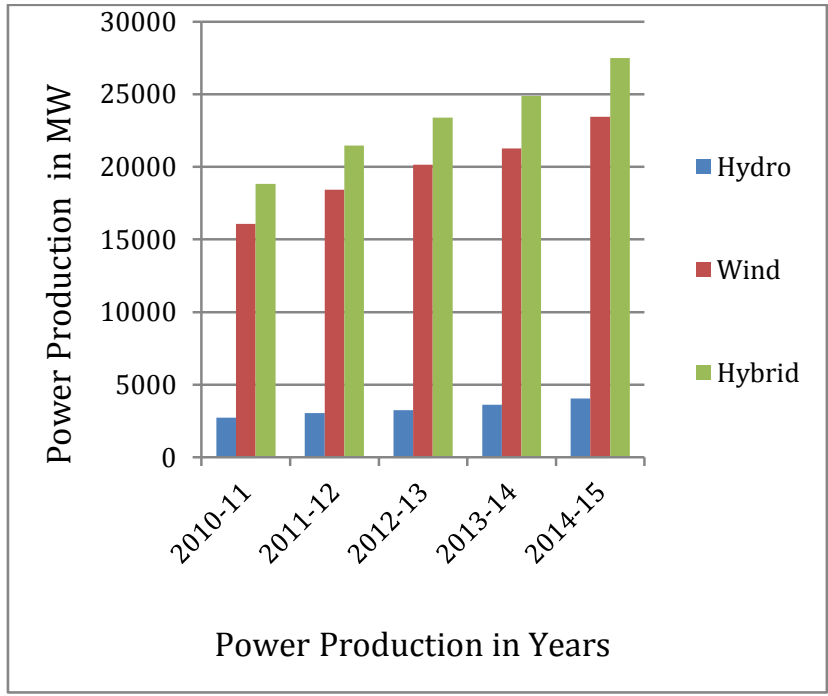

Fig.5 Comparison of solar, hydro and hybrid system

Figure 6 shows the power production by the solar, hydro, and hybrid system. The highest power obtained from the hydro is more than solar system. Figure 6 also shows the power generated from hybrid system is the highest in year of 2014-15, where power production is about $3743 \mathrm{MW}$ from the solar, 4055MW from and 7798 from the hybrid system. 


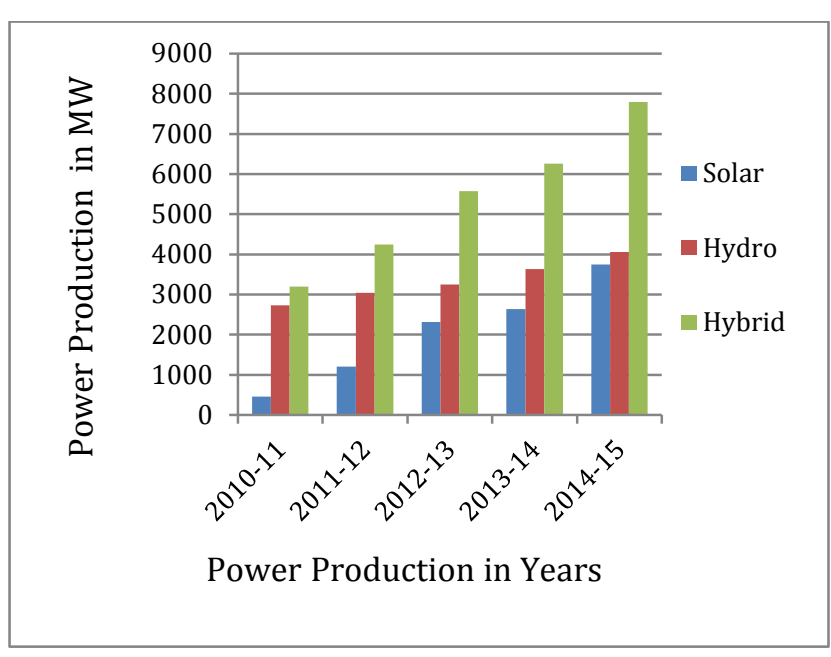

Fig. 5 Comparison of wind, hydro and hybrid system

\section{Conclusion}

As mentioned in the paper the power produced by the combination of solar- wind; wind- hydro; solar-hydro is much greater in comparison to the individual systems. Hence on combining all the three systems the output is expected to be much greater than the corresponding two stage hybrid systems.

\section{References}

B. Khadidja, K Dris, A.Boubeker. and Noureddine S, (2014) Optimisation of a Solar Tracker System for Photovoltaic Power Plants in Saharian region, Example of Ouargla. Energy Procedia.

Vadirajacharya, P.Katti, (2012) Rural Electrification Through Solar and Wind Hybrid System: A Self Sustained Grid Free Electric Power Source, Energy Procedia 142081 - 2087
F. Wenehenubun, (2015) An experimental study on the performance of Savonius wind turbines related with the number of blades, Energy Procedia 68297 - 304.

Y. Shivrath et. al,( 2012) Design \& Integration of Wind-Solar Hybrid Energy System for Drip Irrigation Pumping Application, Vol.2, Issue.4, July-Aug 2012 pp-2947-2950.

Ragheb and A. Ragheb Wind Turbines Theory - The Betz Equation and Optimal Rotor Tip Speed Ratio.

T.Tudorache and L. Kreindler, , (2010) Design of a SolarTracker System for PV Power Plants, Vol. 7, No. 1.

A.Mathias, (2013) Which Solar Panel Type is Best? Mono- vs. Polycrystalline vs. Thin Film. A.T.

Tudorache, L. Kreindler, (2010) Design of a Solar Tracker System for PV Power Plants, Vol. 7, No. 1.

Kumar, S. Ram, (2014) Development of Small Hydro Power in India, IJSRD Vol. 2, Issue 09.

V. Khare, S. Nema, and P. Baredar, (2013) Status of solar wind renewable energy in India, Renewable and Sustainable Energy Reviews 27 1-10.

K.Gaiser ,P. Erickson , (2016) An experimental investigation of design parameters for pico-hydro Turgo turbines using a response surface methodology, Renewable Energy 85 406-418.

S.Williamson, B.Stark, (2013) Performance of a low-head pico-hydro Turgo turbine, Applied Energy 102 1114-1126.

J. Chukwuneke, C. Achebe,(2014) Experimental Investigation on Effect of Head and Bucket Splitter Angle on the Power Output of A Pelton Turbine, Vol.4, No.10. J.Ujam J. Chukwuneke, (2014) Modelling The Effect of Head and Bucket Splitter Angle on The Power Output of A Pelton Turbine ,Aug.. Vol. 5. No. 03.

B. Nasir ., (2013) Design Of High Efficiency Pelton Turbine For Micro hydropower Plant Volume 4, Issue 1, JanuaryFebruary pp. 171-183.

O. Paish (2002)Micro-hydropower: status and prospects. Proc Inst Mec Eng - Part A: J Power Energy;216:31-40 